\title{
Introduction
}

This report presents the latest information from the Living Costs and Food Survey for the 2009 calendar year (January to December). The Expenditure and Food Survey (EFS) was renamed as the Living Costs and Food Survey (LCF) in 2008 when it became a module of the Integrated Household Survey (IHS).

The current LCF is the result of the amalgamation of the Family Expenditure and National Food Surveys (FES and NFS). Both surveys were well established and important sources of information for government and the wider community, charting changes and patterns in Britain's spending and food consumption since the 1950s. The Office for National Statistics (ONS) has overall project management and financial responsibility for the LCF while the Department for Environment, Food and Rural Affairs (DEFRA) sponsors the specialist food data.

The survey continues to be primarily used to provide information for the Retail Prices Index; National Accounts estimates of household expenditure; the analysis of the effect of taxes and benefits, and trends in nutrition. However, the results are multi purpose, providing an invaluable supply of economic and social data.

\section{The 2009 survey}

In 20095,223 households in Great Britain took part in the LCF survey. The response rate was 50 per cent in Great Britain and 56 per cent in Northern Ireland. The fieldwork was undertaken by the Office for National Statistics and the Northern Ireland Statistics and Research Agency.

Further details about the conduct of the survey are given in Appendix B.

The format of the Family Spending publication changed in 2003-04 so that the tables of key results which were found in the main body of the report are now in Appendix A. This year's report includes an overview chapter outlining key findings, two detailed chapters focusing upon expenditure on housing and the impact of equivalising income when calculating results, a fourth chapter looking at trends in household expenditure over time and finally a chapter on expenditure by Output Area Classification (OAC).

\section{Data quality and definitions}

The results shown in this report are of the data collected by the LCF, following a process of validation and adjustment for non-response using weights that control for a number of factors. These issues are discussed in the section on reliability in Appendix B.

Figures in the report are subject to sampling variability. Standard errors for detailed expenditure items are presented in relative terms in Table A1 and are described in Appendix B, section B6. Figures shown for particular groups of households ( for example income groups or household composition groups), regions or other sub-sets of the sample are subject to larger sampling 
variability, and are more sensitive to possible extreme values than are figures for the sample as a whole.

The definitions used in the report are set out in Appendix B, section B4, and changes made since 1991 are described in section B5. Note particularly that Housing Benefit and Council Tax Rebate (rates rebate in Northern Ireland), unlike other social security benefits, are not included in income but are shown as a reduction in housing costs.

\section{Income and Expenditure Balancing}

The LCF is designed primarily as a survey of household expenditure on goods and services. It also gathers information about the income of household members, and is an important and detailed source of income data. However, the survey is not designed to produce a balance sheet of income and expenditure either for individual households or groups of households. For further information on the balancing of income and expenditure figures, see 'Description and response rate of the survey', page 215

\section{Related data sources}

Details of household consumption expenditure within the context of the UK National Accounts are produced as part of Consumer Trends (www.statistics.gov.uk/statbase/Product.asp?vlnk=242). This publication includes all expenditure by members of UK resident households. National Accounts figures draw on a number of sources including the LCF: figures shown in this report are therefore not directly comparable to National Accounts data. National Accounts data may be more appropriate for deriving long term trends on expenditure.

More detailed income information is available from the Family Resources Survey (FRS), conducted for the Department for Work and Pensions. Further information about food consumption, and in particular details of food quantities, is available from the Department for Environment, Food and Rural Affairs, who are continuing to produce their own report of the survey (www.defra.gov.uk/evidence/statistics/foodfarm/food/familyfood/index.htm).

In Northern Ireland, a companion survey to the GB LCF is conducted by the Central Survey Unit of the Northern Ireland Statistics and Research Agency (NISRA). Households in Northern Ireland are over-sampled so that separate analysis can be carried out, however these cases are given less weight when UK data are analysed.

\section{Additional tabulations}

This report gives a broad overview of the results of the survey, and provides more detailed information about some aspects of expenditure. However, many users of LCF data have very specific data requirements that may not appear in the desired form in this report. The ONS can provide more detailed analysis of the tables in this report, and can also provide additional tabulations to meet specific requests. A charge will be made to cover the cost of providing additional information. 
The tables in Family Spending 2009 are available as Excel spreadsheets.

Anonymised microdata from the Living Costs and Food Survey (LCF), the Expenditure and Food Survey (EFS) and the Family Expenditure Survey (FES) are available from the United Kingdom Data Archive. Details on access arrangements and associated costs can be found at www. dataarchive.ac.uk or by telephoning 01206872143. 